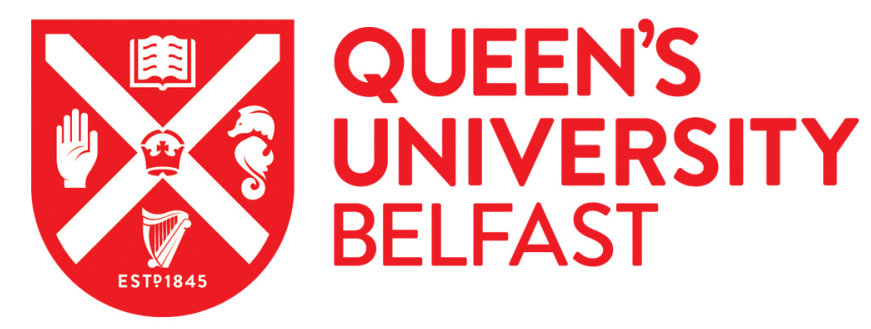

\title{
Early warning systems and rapid response to the deteriorating patient in hospital: a realist evaluation
}

McGaughey, J., O'Halloran, P., Porter, S., Trinder, J., \& Blackwood, B. (2017). Early warning systems and rapid response to the deteriorating patient in hospital: a realist evaluation. Journal of Advanced Nursing, 73(12), 31193132. https://doi.org/10.1111/jan.13367

Published in:

Journal of Advanced Nursing

Document Version:

Peer reviewed version

Queen's University Belfast - Research Portal:

Link to publication record in Queen's University Belfast Research Portal

Publisher rights

Copyright John Wiley \& Sons 2017. This work is made available online in accordance with the publisher's policies. Please refer to any applicable terms of use of the publisher.

\section{General rights}

Copyright for the publications made accessible via the Queen's University Belfast Research Portal is retained by the author(s) and / or other copyright owners and it is a condition of accessing these publications that users recognise and abide by the legal requirements associated with these rights.

Take down policy

The Research Portal is Queen's institutional repository that provides access to Queen's research output. Every effort has been made to ensure that content in the Research Portal does not infringe any person's rights, or applicable UK laws. If you discover content in the Research Portal that you believe breaches copyright or violates any law, please contact openaccess@qub.ac.uk. 
DR JENNIFER MCGAUGHEY (Orcid ID : 0000-0003-2295-1117)

Article type : Original Research: Empirical research - mixed methods

Title: EARLY WARNING SYSTEMS AND RAPID RESPONSE TO THE DETERIORATING PATIENT IN

HOSPITAL: A REALIST EVALUATION

\title{
Running head
}

Early warning systems and rapid response to the deteriorating patient in hospital: a realist evaluation

\author{
Authors \\ Dr Jennifer MCGAUGHEY PhD, RNT, RGN \\ Senior Lecturer \\ School of Nursing \& Midwifery \\ Medical Biology Centre \\ Queen's University Belfast \\ Belfast, Northern Ireland \\ BT9 7BL \\ Email: j.mcgaughey@qub.ac.uk \\ Twitter: Jennifer McGaugh2
}

This article has been accepted for publication and undergone full peer review but has not been through the copyediting, typesetting, pagination and proofreading process, which may lead to differences between this version and the Version of Record. Please cite this article as doi: $10.1111 /$ jan. 13367

This article is protected by copyright. All rights reserved. 
Dr Peter O'HALLORAN PhD, RNT, RGN

Senior Lecturer

School of Nursing \& Midwifery

Queen's University Belfast

Belfast, Northern Ireland

BT9 7BL

Professor Sam PORTER PhD, RN

Department of Social Sciences and Social Work

Bournemouth University

Poole

Dorset

BH12 5BB

Dr John TRINDER MB BCh, MD, FFARCSI, FRCA, FFICM

Consultant Anaesthesia and Intensive Care Medicine

Ulster Hospital, South Eastern Health \& Social Care Trust

Newtownards Road

Dundonald, Belfast

Northern Ireland

BT16 1RH

Professor Bronagh BLACKWOOD PhD, RNT, RGN

Professor

School of Medicine, Dentistry \& Biomedical Sciences

Centre for Experimental Medicine

Wellcome-Wolfson Building

Queen's University Belfast

Belfast, Northern Ireland

BT9 7BL

This article is protected by copyright. All rights reserved. 


\section{Acknowledgements}

We would like to thank members of the Steering group Heather Livingston (Senior Medical Officer), John Trinder (Consultant Anaesthetist) and Joanna McCormick (Critical Care Nurse Consultant) who gave clinical advice and support and to all the hospital staff who participated so willing in the interviews and provision of documentation. We would also like to thank the Northern Ireland Public Health Agency (Health and Social Care, Research and Development) and Critical Care Translational Research Group for support and advice in the conduct of this study.

\section{Conflict of Interest statement}

No conflict of interest has been declared by the author(s).

\section{Funding}

This was a Sandra Ryan Doctoral PhD Fellowship funded by the School of Nursing and Midwifery at Queen's University Belfast.

\section{ABSTRACT}

\section{Aim}

To identify those contexts and mechanisms that enable or constrain the implementation of Rapid Response Systems on acute general hospital wards to recognise and respond to patient deterioration.

This article is protected by copyright. All rights reserved. 


\section{Background}

Rapid Response Systems allow deteriorating patients to be recognised using Early Warning Systems, referred early via escalation protocols and managed at the bedside by competent staff.

\section{Design}

Realist Evaluation

\section{Methods}

The research design was an embedded multiple case study approach of four wards in two hospitals in Northern Ireland which followed the principles of Realist Evaluation. We used various mixed methods including individual and focus group interviews, observation of nursing practice between June - November 2010 and document analysis of Early Warning Systems audit data between May - October 2010 and hospital acute care training records over 4.5 years from 2003-2008. Data were analysed using NiVivo8 and SPPS.

\section{Results}

A cross case analysis highlighted similar patterns of factors which enabled or constrained successful recognition, referral and response to deteriorating patients in practice. Key enabling factors were the use of clinical judgement by experienced nurses and the empowerment of nurses as a result of organisational change associated with implementation of Early Warning System protocols. Key constraining factors were low staffing and inappropriate skill mix levels, rigid implementation of protocols and culturally-embedded suboptimal communication processes.

\section{Conclusion}

Successful implementation of Rapid Response Systems was dependent on adopting organisational and cultural changes that facilitated staff empowerment, flexible implementation of protocols and ongoing experiential learning.

This article is protected by copyright. All rights reserved. 


\section{Key Words:}

realistic evaluation, early warning systems, rapid response systems, nursing, patient deterioration, enabling and constraining factors, patient recognition, escalation protocols.

\section{SUMMARY STATEMENT}

\section{Why is this research needed?}

- Research has provided limited clinical answers to explain why such a conceptually logical model as RRS does or does not work in practice.

- There is a need to understand those contexts and mechanisms that have an impact on achievement of desired RRS outcomes.

- No research to date has used a realist evaluation approach to test the RRS programme theory.

\section{What are the key findings?}

- The use of clinical judgement by experienced nurses enabled early recognition of patients.

- Implementation of EWS protocols facilitated successful organisational change.

- Low staffing levels, inappropriate skill mix, rigid implementation of protocols, cultural communication processes constrained RRS implementation.

\section{How should the findings be used to influence policy/practice/research/education?}

- Staff empowerment is central to organisational change initiatives.

- Education of staff needs to be ward-based and ongoing to facilitate learning.

- Flexible implementation of protocols facilitates use of clinical judgement by trained staff.

This article is protected by copyright. All rights reserved. 


\section{INTRODUCTION}

The concept of the Rapid Response System (RRS) was developed by expert consensus opinion as a solution to address suboptimal ward-based care and reduce the number of preventable hospital deaths (DoH 2000). The framework provides a mechanism to improve recognition of and clinical response to, patients who deteriorate in hospital. It entails a systematic change in the way hospitals deliver care. Essential features of the RRS comprise four interrelated systems: an afferent arm which is the "physiological assessment" and "triggering" mechanism; an efferent arm which provides competent personnel and resources at the bedside and treatment if necessary; a governance/administrative structure to supply and organize resources; and a mechanism to evaluate crisis antecedents and promote hospital process improvement to prevent future events (DeVita et al. 2006). Implementing all components of the RRS should ensure that most deteriorating hospital patients are identified early through the use of Early Warning System (EWS) charts; referred early using protocolised graded response strategies; and managed by professionals with appropriate specialist knowledge and skills in acute care. The intention is to provide safe, effective and equitable acute care to all patients in hospital.

\section{Background}

RRSs have been adopted internationally despite the lack of high grade evidence to support their effectiveness (McGaughey et al. 2007; Chan et al. 2010, McNeill \& Bryden 2013, Alam et al. 2014). Studies have been predominately retrospective, uncontrolled or historically controlled before-and-after studies (Moon et al. 2011, Howell et al. 2012, Al-Qahtani et al. 2013, Etter et al. 2014, Sefton et al. 2015). To date, only two randomised controlled trials (RCTs) have evaluated RSS (Priestly et al. 2004, MERIT et al. 2005). These studies have focused primarily on measuring patient outcomes (unanticipated ICU admission, death,

This article is protected by copyright. All rights reserved. 
cardiac arrest) of the efferent arm of the RRS, with limited assessment of the context, processes or mechanisms leading to the outcomes ie the afferent arm. Consequently, research has provided limited clinical answers to explain why such a conceptually logical model as RRS does or does not work in practice. To address this gap in the evidence, we set out to explore the implementation and delivery of components of the RRS in two Northern Ireland hospitals to identify those contexts and mechanisms that enable and constrain the recognition, referral and management of deteriorating patients in practice using a realistic evaluation approach.

\section{THE STUDY}

\section{Aim}

To test the RRS programme theory against actual practice components of the RRS implemented to identify those contexts and mechanisms which have an impact on the successful achievement of desired outcomes in practice.

\section{Design}

Realistic Evaluation (RE) is a theory driven approach used to explore and explain programme systems and the relationship between context $(\mathrm{C})$, mechanism $(\mathrm{M})$ and the outcomes $(\mathrm{O})$. RE assumes that all programmes have an underlying theory to explain how a particular intervention is 'meant' to work. The purpose of the RE approach is to identify the underlying programme theory and test hypothesised causal relationships between the CMO concepts by gathering data to clarify and refine the theory (Pawson \& Tilley 1997).

Stage one involved: (a) describing the RRS theory by undertaking a realist review of the literature; (b) interviewing people who had introduced the RRS to understand how the programme was meant to work; and (c) generating hypotheses of how it was supposed to work (developing theoretical propositions). Stage two involved collecting data from multiple

This article is protected by copyright. All rights reserved. 
sources (hospital staff and documents) to determine how it actually worked in practice. Stage three involved establishing causal relationships to explain how in different contexts (C) various mechanisms $(\mathrm{M})$ are triggered to generate outcome $(\mathrm{O})$ patterns (typically called CMO configurations).

We used a multiple case study of two hospital sites with embedded subgroups of two hospital wards on each site (Figure 1). The sites were large hospitals in Northern Ireland with a similar Intensive Care Unit (ICU) provision and at that time neither hospital had funding to implement a multidisciplinary Critical Care Outreach Service (CCOS) to support ward staff with critical care staff competent in managing patient deterioration (Supplementary information Table 1). The sites had implemented Early Warning Systems (EWS) across their acute wards and operated Acute Life Threatening Events- Recognition and Treatment (ALERT) training for staff (Smith et al. 2002). In each site, one medical and one surgical ward were selected to represent a high and low risk ward based on the number of unanticipated ICU admissions over the previous year from the hospital admission records. Recruiting subgroups based on type of ward and level of risk allowed us to capture broad variation in potential factors that may have contributed to its success or failure.

\section{Participants}

Stage 1 Interviews: We recruited a purposive sample of 14 medical and nursing policymakers with a key role in the strategic planning and implementation of RRS, medical and nursing staff who had championed the implementation of EWS and the ALERT training programmes and external experts (Minister of Health, ALERT expert) to explore how RRS was implemented in practice. Participants were personally invited for face to face interview by letter by JM. This was followed up by a phone call to ascertain agreement to participate.

This article is protected by copyright. All rights reserved. 
Stage 2 Interviews: Individual face to face interviews were undertaken with a purposeful sample of 28 key informants (senior managers, managers, junior doctors, EWS and ALERT champions), who were invited by letter and followed up by phone call, to determine their views of the conjectured RRS theories and to compare these with their actual experiences. Five key informants ( 2 in case site $1 \& 3$ in case site 2) interviewed in Stage 1 also participated in key informant interviews in Stage 2 to clarify and explain the findings from Stage 1 further in relation to the conjectured RRS theoretical assumptions. Focus group interviews were conducted with 34 key informants (staff nurses, student nurses or health care assistants) who had not been interviewed in Stage 1 or Stage 2 individual interviews and agreed to participate following a letter of invitation distributed to all ward staff by ward managers (Table 1). Staff who opted-in by returning reply slips were followed up by phone call. Separate focus groups were undertaken for staff nurses, student nurses and health care assistants to overcome the negative impact of power differences between professionals (Stewart et al 2007).

Stage 2 non-participant observation: All ward staff were provided with a letter of invitation from ward managers to participate in the observation period. Those staff who opt-in were followed up by phone call and rostered to work on the observational days.

\section{Data collection}

The three stages of the RE process guided the data collection and analysis. The study protocol outlines the methods in full detail (McGaughey et al. 2010). A synopsis of the methods is presented here. The organisational structure reported here was in place in 2010 during data collection.

This article is protected by copyright. All rights reserved. 


\section{Stage 1: Developing Theoretical Propositions}

To develop the theoretical propositions, we undertook a realist review of the literature; interviewed key senior policymakers and managers; and obtained key policy and training documents to provide contextual information.

Realist Review: The realist review was undertaken (McGaughey submitted for JAN publication) prior to the interviews to illustrate the underpinning theory of how RRS is supposed to work and reveal initial RRS theoretical propositions (Table 2). The findings were used to guide the interviews.

Interviews: The semi-structured interview schedule was structured using the theoretical propositions identified during the realist review and from the implementation and sustainability framework devised by Greenhalgh (2004). Digitally recorded interviews (lasting approximately one hour) were conducted between July - October 2008 in agreed venues, principally participants' offices.

Contextual documentation: We obtained information from the acute care training records over 4.5s period from 2003-2008 relating to numbers and categories of staff who were trained including inter-professional ratios for each course, grades of staff trained, number of staff trained per ward and in Directorates since the ALERT course was implemented in the hospital (Table 3). Data was analysed in SPSS (2008). In addition, photocopies of EWS policies were also obtained.

\section{Stage 2: Testing Theoretical Propositions}

Having established theoretical propositions of how the RRS was intended to work, stage two involved collecting data during interviews with hospital staff and observation of practice between June - November 2010, this time with a focus on whether the RRS was working as it should; and from EWS audits during May 2010 - October 2010 to provide contextual 
information on trends in adherence.

Interviews: A semi-structured interview schedule was developed following analysis of Stage 1 findings and modified for individual and focus group interviews to contextualise the questions to obtain different key informant perspectives (See supplementary information file 1). Interviews were undertaken by JM and lasted approximately 30 minutes; they were digitally recorded and conducted in a private room

Nonparticipant Observation: Nonparticipant observation of healthcare staff recording EWS charts was undertaken by JM on each of the four wards for an average of 8 hours (33 hours) from fixed points to minimise intrusion (See Supplementary information table 2). An observation guide was developed that captured information on ward infrastructure, working conditions and organisational processes (Greenhalgh et al. 2004). Information regarding the study was provided for patients on posters displayed on the wards.

EWS Audit Documentation: With permission from Directorate managers, we obtained copies of the EWS audits that were conducted in the four wards to report on compliance rates, reasons for low compliance and action plans to improve compliance where data existed.

\section{Ethics}

Ethical approval was obtained from the Office of Research Ethics Committee Northern Ireland ((Ref: 08/NIR01/15). The study was conducted under the requirements of the Research Governance Framework approved by the hospital Trusts and Queens University Belfast. Informed consent was obtained from all individuals who agreed to participate in the interviews and observation period. Documentary evidence obtained from the case sites did not contain personal information which ensured that the names of individuals were not known to the researcher and remained confidential.

This article is protected by copyright. All rights reserved. 


\section{Data analysis}

Stage 1 and 2: Data analysis

Interviews were digitally recorded and transcribed verbatim to ensure consistent and accurate recording of data. The Stage 1 transcripts and observation data were coded according to the seven key factors (external context and agencies; internal context and organisation readiness; communication; adaptors and adoption; innovation; implementation process and consequences) from the Greenhalgh framework (2004). The emergent themes from the Stage 2 transcripts were categorised in the key components of the RRS theoretical propositions. Coding and categorisation in Stage 1 and Stage 2 allowed indexing and retrieval in NVivo8 software (NVivo 2008).

\section{Stage 3: Cross Case Comparison \& Mid-range theory development}

The synthesised data from the interviews, focus groups, observation and documentation were compared within and across sites and subgroups to provide an understanding of the similarities and differences. Cross case synthesis and triangulation of Stage 1 and 2 findings through a process of constant reflection and critique to compare competing explanations allowed us to refine CMO configurations (McEvoy \& Richards 2003). These CMO configurations explained the causal mechanisms which produced outcomes in different contexts. Interpretation of these CMOs using an iterative and cyclical process facilitated theory refinement and the development of a mid-range theory to explain how and why the programme works in certain circumstances for certain individuals (Pawson \& Tilley 1997).

\section{Validity and Reliability}

The realist review identified RRS theoretical propositions for testing and the Greenhalgh framework (2004) structured data collection and analysis to enhance validity and reliability. The interpretation of interview coding and categories were cross-checked by BB to enhance

This article is protected by copyright. All rights reserved. 
reliability and reduce bias. Credibility was ascertained through the use of triangulation and respondent validation of Stage 1 findings with key policymakers in Stage 2. Documentary evidence of EWS and ALERT records provided an audit trail to enhance dependability and confirmability of findings. The emerging RRS conceptual themes were cross-checked the by the steering group members.

\section{RESULTS}

\section{RRS Theoretical Propositions}

The realist review and policymaker interviews identified key intervention components that were thought to lead to successful implementation and sustainability of the RRS afferent arm: early recognition of deterioration using EWS charts; early referral using graded response protocols; and education or ALERT training to improve the effectiveness of care offered by early responders. The initial impetus for these initiatives was reported to have arisen from concerned staff and managers in the hospitals but was not generally supported until patient safety directives were prioritised by the Department of Health (DoH) and a cultural change occurred. These changes to establish Clinical Governance in hospitals resulted in new structures and roles to improve and develop patient safety initiatives within existing budgets. Hospitals then implemented these aspects of the intervention as a Priority for Action (PfA) to reduce the annual number of cardiac arrest rates. To effectively implement the planned changes managers recognised the importance of raising awareness, effective ward leadership, EWS and ALERT training and continued support for staff. The implementation of EWS was perceived by policymakers as an opportunity to change the task orientated culture of observations to a structured patient assessment approach and change mind-sets to improve inter-professional understanding and referral with: (i) objective criteria; and (ii)

communication using the Situation, Background, Assessment and Recommendation (SBAR)

This article is protected by copyright. All rights reserved. 
tool (IHI 2016). In addition, ALERT champions perceived that the standardised educational package adopted by both hospitals provided staff with a structured assessment framework, improved confidence, knowledge, skills, communication and teamwork. Theoretical propositions developed from this evidence provided an understanding of how RRS was supposed to work in practice. However, policymaker interviews, ALERT audit data and research evidence (Odell et al. 2009, O'Leary et al. 2010, Azzopardi et al. 2011, Shearer et al. 2012, Radeschi et al. 2015) highlighted that traditional hierarchical referral cultures, routine observation culture, competing workloads, low staffing levels, low nursing confidence and a lack of communication and interdisciplinary teamwork were factors that constrained implementation of the underlying propositions in practice. These factors were tested in Stage 2 to develop further and refine CMO configurations and RRS theory to explain those factors that enabled or constrained the implementation of EWS or ALERT in practice.

\section{Testing and refining $R R S$ Theories}

\section{Early Recognition}

In both sites there was a phased implementation of EWS charts and staff training to improve awareness, compliance and standardise the recording of observations on wards. The leadership role of the ward manager was perceived by hospital managers, senior nurses and champions as key to driving changes at ward level. However, hospital managers reported that the lack of change to the routine task of recording observations was associated with workload pressures due to continual resource issues to ensure adequate staffing levels for the level of patient dependency on general wards and the rigid application of recording observations implemented with clinical Governance in hospitals. As a result, staff employed several mechanisms to ensure workload was completed in this demanding and changing

This article is protected by copyright. All rights reserved. 
organisational context. Experienced nurses would delegate the task of recording observations of patients' clinical status (heart rate, blood pressure etc.) to junior nurses, student nurses or health care assistants (HCAs) as part of the ward routine to enable them to care for the sickest patients on the ward. Managers felt this resulted in a continuing reliance by staff solely on electronic equipment (rather than holistic assessment) with limited interpretation of the clinical observations or knowledge of appropriate action. Staff nurses reported that the pressure to juggle time-rigid completion of observations with other ward priorities resulted in charts not always being completed accurately or at an exact time to comply with the instructions on the EWS charts. Consequently, staff reported they did not always record the time of measurements on clinical observation charts and this meant that EWS audits did not meet compliance rates set by the hospital. Managers and champions recognised that EWS training, human error, competing workloads and existing custom and practice in relation to patient observations were factors that had an impact on EWS chart compliance (Table 4).

\section{Early Referral}

A clearly defined trigger and response strategy was implemented in hospitals to standardise the decision making and referral process. In providing a mechanism for nurses to ensure patients were reviewed within the appropriate timeframe, the EWS protocol empowered nurses and gave them confidence to challenge response delays or refer to a senior level based on their interpretation of the situation. This cultural change provided nurses with clear guidelines and authority to support decisions; which managers perceived reduced the potential fear associated with contacting the doctor and provided a structure to the system which facilitated decisions to call for help. This was particularly evident for higher trigger scores. However, at low trigger scores the protocol was used flexibly by nursing staff to refer patients based on their clinical judgment. Clinical judgement was underpinned by pattern 
recognition and intuition based on subjective criteria of knowing the patient, normal ward practices, the context (situation, time of day, availability of medical staff and whether doctors were familiar with the patient) or individual circumstances and clinical experience. Managers and staff nurses reported that the referral protocol was viewed as a guideline and recognised that clinical judgement and individual discretion were used when referring lower trigger scores. However, doctors and managers perceived that delays in referrals were associated with junior nurses' lack of confidence, waiting to recheck observations and not reporting a single deranged physiological parameter. In both sites, ward managers and staff nurses stated that agency staff and student nurses were mainly responsible for not reporting EWS scores, high parameters or deranged observations straight away (often students provided a list of observations just prior to handover).

An informal, cultural communication process was used by nurses during the daytime to refer patients to junior or senior medical staff as it was the most effective way to obtain a response. Nurses reported that communication reported to doctors was comprehensive. However, junior doctors stated that referral information was inconsistent (depending on the individual and experience) and often required having to prise information from nurses. Nurses did not use the SBAR communication tool during the day as there was limited use for a formal communication tool when there was no CCOS in place and ward doctors were familiar with patients. At night in both case sites referrals to doctors required an SBAR call to the Hospital at Night team. The use of SBAR at night required nurses to refer patients based on subjective criteria which was not compatible with a formal process requiring justification for help, was time consuming and elicited limited immediate response from doctors out of hours. Communication difficulties highlight the gaps in understanding each other's roles and responsibilities (McCrory et al. 2015, Michalec et al. 2015).

This article is protected by copyright. All rights reserved. 


\section{Early Response}

In both sites ALERT training was adopted and driven by champions in existing human resources to ensure staff managed patient deterioration appropriately at the bedside within their level of competence. Managers felt that ALERT training improved inter-professional communication and nurses' knowledge, skills and confidence to provide basic pre-emptive management while waiting for help. However, doctors and nurses felt they primarily learnt from clinical ward experience. As a result, there was a recognised need by nurses for ongoing education on the wards, for placement opportunities to gain experience and to have a transparent educational role on the ward to facilitate ongoing learning and link course theory to practice. The nurse education role on wards at the time of the study was subsumed in a management role and as a result education was not viewed as a high priority, staff were not released for training due to staff shortages, there was limited competency based teaching on the wards and the primary educational focus was on attendance at mandatory training courses.

Policymakers and experts felt that in most cases deteriorating patients did trigger a referral and a clinical assessment was made by junior staff. However, in a small number of cases there continued to be problems ensuring an effective and timely response to patient deterioration. Hospital managers associated these delays with nurses' confidence in initiating the response, or doctors not complying or responding to the trigger mechanism. Nurses stated that their lack of confidence in obtaining a response from junior doctors out of hours meant they often decided not to refer but to manage the situation on the ward. Indeed, key informants reported that there was a degree of uncertainty over making a decision to manage or refer patients. This uncertainty was associated with determining whether the situation was manageable when the EWS score and clinical judgment conflicted. In both sites 
organisational practices and beliefs encouraged junior medical staff to assess and manage patient care within their level of competence prior to calling for senior help. As a result the response in many cases was to manage situations on the wards within their own realm of competence and to re-evaluate. An ALERT expert reported that most of the time the decision to reassess was an appropriate response to a transient change. However, on a small number of occasions staff failed to rescue patients as a result of making an incorrect decision that there was no underlying problem or to re-evaluate. This was perhaps a result of the most junior medical and nursing staff being the predominant responders.

\section{Clinical \& Process Outcomes}

Standardised recording practices, protocolised referrals and education were implemented to improve accuracy and completeness of observation recording in hospitals and to reduce the number of cardiac arrests. In both sites, audit records on EWS compliance and cardiac arrest rates were maintained and reported as part of the Clinical Governance process. Hospital managers, ward managers, senior nurses, ALERT champions and staff nurses felt that changing cultural attitudes to resuscitation had increased the number of pre-arrest calls and proactive Do Not Resuscitate (DNR) management plans had contributed to the reduction in the number of cardiac arrests. However, policymakers, experts and hospital managers recognised that it was difficult to attribute these figures to any one intervention due to the complex interplay of numerous factors in the healthcare environment and no records of DNR orders maintained in the hospitals at that time. Documentary evidence on cardiac arrest rates across hospitals were not reviewed in this study.

This article is protected by copyright. All rights reserved. 
Analysis of EWS compliance records showed an increase in the accuracy and completeness of recording practices over the five-month data collection period (Table 5). Similarly, hospital managers reported that the EWS audits showed improved compliance rates, although they felt that charts continued to be inaccurate and incomplete as the frequency of observations to be recorded or actions taken for a triggered score were not documented. However, managers in both sites questioned the representativeness of the $100 \%$ EWS compliance rates captured by audit, as there continued to be incidents reported. Staff nurses perceived the EWS audit to be a burdensome waste of time and were not aware of feedback on compliance scores. They therefore viewed the audit process as a paper exercise of limited value in providing safe, high-quality care. Consequently, properly completed EWS charts were purposively selected each week to ensure a high compliance score in the audit and avoid further paperwork involving writing action plans to address non-compliance.

\section{DISCUSSION}

The RE found that RRS early recognition theoretical assumptions worked when experienced staff used the EWS protocols flexibly alongside contextual knowledge at low trigger scores to guide and inform their decision-making. Staff experience has been highlighted in this study and others as an important contributing factor to effective recognition and referral (Massey et al. 2014, Braaten 2015). However, when observations were undertaken by junior staff and HCAs, the early recognition and referral procedures did not work in practice (Ludikhuize et al. 2011, Mackintosh et al. 2012, Roberts et al 2014, Radeschi et al. 2015, Johnston et al. 2015). This was a result of junior nursing staff rigidly applying the trigger criteria with limited knowledge or skills in patient assessment. Rigid application of EWS increased the number of false positive calls and medical workload as a result of poor sensitivity and specificity of the tools in practice (Azzopardi et al. 2011, Mandell et al. 2015). This perpetuated a ritualistic and

This article is protected by copyright. All rights reserved. 
mechanistic approach to the recording of observations which meant cues were often missed and physiological parameters were reported in isolation. As a result junior staff were less likely to recognise and refer EWS scores to senior staff (Azzopardi et al. 2011, Pattison \& Eastham 2011). The existing literature suggests that junior staff may lack confidence and experience in integrating theoretical knowledge in the clinical context ( $\mathrm{DoH} 2013$ ) to safely make these decisions (Shearer et al. 2012; Massey et al. 2014).

Inadequate staffing levels and skill-mix on wards has been highlighted in this study and others as causal factors contributing to poor recognition and management of deteriorating ward patients (Donohue and Endacott 2010, Johnston et al. 2015) as a result of a lack of time to observe or follow up deteriorating patients (Hands et al. 2013, Jeddian et al. 2016). Research evidence highlights a strong association between mortality rates and improved staff ratios (NICE 2014, National Quality Board 2016).

Implementation of the EWS protocol in this study empowered experienced nurses to call for help and to refer patients appropriately based on the trigger criteria and clinical judgement. The use of clinical judgement was viewed by staff as an important part of professional decision making to ensure the most effective use of time and resources in managing patient care. Research evidence recognises the importance of intuitive knowledge and pattern recognition (Pattison \& Eastham 2011, Mackintosh et al. 2012, Brady \& Goldenhar 2014, Clifton et al. 2015). As a result, the flexible use of EWS protocols in practice will have an impact on the implementation and utility of the National Early Warning System (NEWS) (RCP 2012) to standardise assessment and response of acute illness in hospitals.

This article is protected by copyright. All rights reserved. 
Referral processes tended to be informal. Staff referred to junior doctors on the ward rather than using the SBAR communication tool which they found to have limited response benefit when contacting doctors out of hours or doctors who were unfamiliar with the patient. SBAR has not been widely adopted or used by nurses as it requires justifying the need for help which nurses find difficult when concerned about a patient (Ludikhuize et al. 2011, Mackintosh et al. 2012, Smith et al. 2014, Bingham 2015). Evidence suggests that this hierarchical communication and traditional response systems often delay calls for help and compromises care (Calzacca et al. 2010, Azzopardi et al. 2011, Radeschi et al. 2015, Braaten 2015).

The early response theoretical assumptions worked when nurses and doctors were given acute care training to improve awareness, knowledge and confidence in the management of patient deterioration. With regards to competence it was recognised that it is the responsibility of each individual to know their own level. This resulted in difficulties for junior doctors and nurses knowing when to when to manage or call for help. Delays in referral or response to patient deterioration were attributed to nursing staff making informed decisions based on their clinical judgement to wait and repeat observations prior to referral, or junior staff making informed decisions to manage the patient on the ward within their own realm of competence. Often these decisions to reassess or manage patients on the ward were correct but on a small number of occasions resulted in failure to rescue patients.

Increased educational awareness changed the cultural response practices in the hospitals as staff called for help earlier and proactively managed patients who may not have benefited from further resuscitative or invasive procedures by discussing palliative care options. These changes in practice were attributed to the reduction in the number of cardiac arrests in the

This article is protected by copyright. All rights reserved. 
hospitals. This evaluation and other studies highlight the difficulty of ascertaining whether reductions in cardiac arrest numbers were due to increased DNR orders or caused by improved outcomes due to timely treatment (Calzavacca et al. 2010, Oglesby et al. 2011, Downar et al. 2013, Pattison et al. 2015).

\section{Limitations}

The focus group interviews with staff nurses, student nurses and HCAs were restricted to two or three individuals at anytime due to ward staffing levels at the time of the study. This may have limited the group dynamics and generalisability of the findings. In addition, the observation of staff and ward practices may have resulted in variations of behaviours. To minimise the Hawthorne effect JM visited the ward on numerous occasions to familiarise with staff prior to the observation period.

\section{CONCLUSION}

The findings highlight that implementation and use of protocols to standardise care and inform decision making will never be straightforward because individual experience, sociocultural and contextual factors have an impact on clinical decisions. As a result, organisations need to provide true multidisciplinary education and ensure experienced staff record, report and manage patient deterioration. This will require an investment in human resources to address current staffing issues and recognition by policymakers that the provision of high-quality care costs. This is an important consideration given the findings of reports on the quality and provision of care in England (Berwick 2013, DoH 2013, Francis 2013) which characterise the importance of a good culture of care. Pawson and Tilley (1997) suggest that the provision of reasons and resources enables programme participants to change.

This article is protected by copyright. All rights reserved. 
Since completion of this study the case site hospitals have implemented the National Early Warning System (NEWS) to standardise the recognition and referral process. Further training and educational initiatives have resulted in the development of EWS training alongside an online SBAR training package. CCOS have been implemented across both case sites to improve response and management of deterioration at the bedside. Acute care training in ALERT has continued despite limited human resources and funding. A recent review of acute care training in the management of patient deterioration has been undertaken regionally due to the variation in educational provision and funding across the hospitals (Education Commissioning Group 2017). However, multiprofessional educational opportunities continue to be restricted by block training of junior doctors to accommodate organisational rotation practices. The success and sustainability of RRS requires further organisational changes to improve staffing levels and interprofessional education to address the main factors constraining implementation in practice.

\section{Author Contributions:}

All authors have agreed on the final version and meet at least one of the following criteria (recommended by the ICMJE*):

1) substantial contributions to conception and design, acquisition of data, or analysis and interpretation of data;

2) drafting the article or revising it critically for important intellectual content.

* http://www.icmje.org/recommendations/

This article is protected by copyright. All rights reserved. 


\section{REFERENCES}

Alam, N., Hobbelink, E.L., van Tienhoven, A.J., van de Ven P.M., Jansma, E.P., \& Nanayakkara P.W. (2014). The impact of the use of the Early Warning Score (EWS) on patient outcomes: a systematic review. Resuscitation, 85(5), 587-94.

Al-Qahtani, S., Al-Dorzi, H.M., Tamim, H.M., Hussain, S., Fong, L., Taher, S., ...Arabi Y. (2013). Impact of an intensivist-led multidisciplinary extended rapid response team on hospital-wide cardiopulmonary arrests and mortality. Critical Care Medicine, 41,506-17.

Azzopardia, P., Kinney, S., Moulden, A., Tibballs, J. (2011). Attitudes and barriers to a Medical Emergency Team system at a tertiary paediatric hospital. Resuscitation, 82, 167-174.

Berwick, D. (2013). A promise to learn- a commitment to act. Improving the safety of patients in England. National Advisory Group on the Safety of Patients in England. Department of Health. London: Williams Lea. Retrieved from https://www.gov.uk/government/uploads/system/uploads/attachment_data/file/226703/Berwi ck_Report.pdf

Bingham, G., Fossum, M., Barratt, M., \& Bucknall T. (2015). Clinical review criteria and medical emergency teams: evaluating a two-tier rapid response system. Critical Care Resuscitation, 17(3), 167-173.

Braaten, J.S. (2015). Hospital System Barriers to Rapid Response Team Activation: A Cognitive Work Analysis. American Journal of Nursing, 115( 2), 22-32.

This article is protected by copyright. All rights reserved. 
Brady, P.W., \& Goldenhar, L.M., (2014). A qualitative study examining the influences on situation awareness and the identification, mitigation and escalation of recognised patient risk. BMJ Quality \& Safety, 23,153-161. doi:10.1136/bmjqs-2012-001747 153.

Calzavacca, P., Licari, E., Tee, A., Egia, M., Downey, A., Quacha, J., ...Bellomo R. (2010). The impact of Rapid Response System on delayed emergency team activation patient characteristics and outcomes-A follow-up study. Resuscitation, 81, 31-35.

Chan, P.S., Jain, R., Nallmothu, B.K., Berg R.A., \& Sasson, C. (2010). Response Teams: A Systematic Review and Meta-analysis. Archives Internal Medicine, 170(1),18-26. doi: 10.1001/archinternmed.2009.424.

Clifton, D.A., Clifton, L., Sandu, D-M., Smith, G.B., Tarrassenko, L., Vollam, S.A., \& Watkinson P. (2015). 'Errors' and omissions in paper based early warning scores: the association with changes in vital signs—a database analysis. BMJ Open, 5: e007376. doi:10.1136/bmjopen-2014-007376

Department of Health. (2000). Comprehensive Critical Care: a Review of Adult Critical Care Services. London: Department of Health.

Department of Health. (2013). Hard Truths The Journey to Putting Patients First Volume Two of the Government Response to the Mid Staffordshire NHS Foundation Trust Public Inquiry: Response to the Inquiry's Recommendations. London: The Stationary Office.

DeVita, M.A., Bellomo, R., Hillman, K., Kellum, J., Rotondi, A., Teres, D., .....Galhotra, S. (2006). Findings of the First Consensus Conference on Medical Emergency Teams. Critical Care Medicine, 34(9), 2463-2478.

Donohue, L.A., \& Endacott, R. (2010). Track, trigger and teamwork: Communication of This article is protected by copyright. All rights reserved. 
deterioration in acute medical and surgical wards. Intensive and Critical Care Nursing, 26, $10-17$.

Downar, J., Barua, R., Rodin, D., Lejnieks, B., Gudimella, R., McCredie, V., Hayes, C., \& Steel, A. (2013). Changes in end of life care 5 years after the introduction of a rapid response team: multicentre retrospective study. Resuscitation, 84, 1339-1344.

http://dx.doi.org/10.1016/j.resuscitation.2013.03.003

Education Commissioning Group. (2017). Review of the education and support of nurses and midwives to identify and manage the deteriorating patient. Unpublished draft, Education Commissioning Group, DHSSPS, Belfast.

Etter, R.,Takala, J., \& Merz, T.M. (2014). Intensive care without walls - introduction of a Medical Emergency Team system in a Swiss tertiary care centre. Swiss Medical Weekly,144, w14027

Francis, R. (2013). Report of the Mid Staffordshire NHS Foundation Trust Public Enquiry. London: The Stationary Office.

Greehalgh, T., Robert, G., Macfarlane, F., Bate, P., \& Kyriakidou, O. (2004). Diffusion of Innovations in Service Organisations: systematic review and recommendations. Milbank Quarterly, 82, 581-629.

Hands, C., Reid, E., Meredith, P., Smith, G.B., Prytherch, D.R., Schmidt, P.E, \& Featherstone, P.I. (2013). Patterns in the recording of vital signs and early warning scores: compliance with a clinical escalation protocol. BMJ Quality \& Safety, 22,719-726. doi:10.1136/bmjqs-2013-001954

This article is protected by copyright. All rights reserved. 
Howell, M.D., Ngo, L., Folcarelli, P., Yang, J., Mottley, L., Marcantonio, E.R., Sands, K.E., Moorman, D., \& Aronson, M.D. (2012). Sustained effectiveness of a primary-teambased rapid response system. Critical Care Medicine, 40, 2562-8.

Institute for Healthcare Improvement. (2016 ). SBAR toolkit. Retrieved from http://www.ihi.org/resources/Pages/Tools/sbartoolkit.aspx

Jeddian, A., Hemming, K., Lindenmeyer, A., Rashidian, A., Sayadi, L., Jafari, N.,....\& Marshall, T. (2016). Evaluation of a critical care outreach service in amiddle-income country: A stepped wedge cluster randomized trial and nested qualitative study. Journal of Critical Care, 36, 212-217. http://dx.doi.org/10.1016/j.jcrc.2016.07.018

Johnston, M.J., Arora, S., King, D., Bouras, G., Almoudaris, A.M., Davis, R., \& Darzi, A. (2015). A systematic review to identify the factors that affect failure to rescue and escalation of care in surgery. Surgery, 157(4), 752-763. http://dx.doi.org/10.1016/j.surg.2014.10.017

Ludikhuize, J., de Jonge, E., \& Goossens, A. (2011). Measuring adherence among nurses one year after training in applying the Modified Early Warning Score and Situation-BackgroundAssessment-Recommendation instruments. Resuscitation, 82,1428-1433. doi:10.1016/j.resuscitation.2011.05.026

Mackintosh, N., Rainey, H., \& Sandall, J. (2012). Understanding how rapid response systems may improve safety for the acutely ill patient: learning from the frontline. BMJ Quality \& Safety, 21, 135e144. doi:10.1136/bmjqs-2011-000147

This article is protected by copyright. All rights reserved. 
Mandell, I.M., Bynum, F., Marshall, L., Bart, R., Gold, J.I., \& Rubin, S. (2015). Pediatric

Early Warning Score and unplanned readmission to the pediatric intensive care unit. Journal of Critical Care, 30, 1090-1095. http://dx.doi.org/10.1016/j.jcrc.2015.06.019

Massey, D., Aitken, L.M., \& Chaboyer, W. (2015). The impact of a nurse led rapid response system on adverse, major adverse events and activation of the medical emergency team. Intensive and Critical Care Nursing, 31, 83-90. http://dx.doi.org/10.1016/j.iccn.2014.11.005

McCrory, M.C., Aboumatar, H.A., \& Hunt, E.A. (2015). Communication at Pediatric Rapid Response Events: A Survey of Health Care Providers. Hospital Pediatrics, 5(6), 301-308.

McEvoy, P. \& Richards, D. (2003). Critical Realism: a way forward for evaluation research in nursing? Journal of Advanced Nursing, 43(4),411-420.

Michalec B., Reinhold N., Dressler R., Laskowski-Jones L., Adarve L. \& Elliott D. (2015). Barriers to and Facilitators of Interprofessional-Interdepartmental Interventions: Unearthing Departmental Culture. American Journal of Medical Quality, 30(2), 126-134. doi: $10.1177 / 1062860613518963$

McGaughey, J., Alderdice, F., Fowler, R., Kapila, A., Mayhew, A. \& Moutray, M. (2007). Outreach and Early Warning Systems (EWS) for the prevention of Intensive Care admission and death of critically ill adult patients on general hospital wards. Cochrane Database of Systematic Reviews 3. DOI: 10.1002/14651858.CD005529.pub2.

McGaughey, J., Blackwood, B., O’Halloran, P., Trinder, T.J. \& Porter, S. (2010). Realistic

This article is protected by copyright. All rights reserved. 
Evaluation of Early Warning Systems and Acute Life-threatening Events: Recognition and Treatment course for early recognition and management of deteriorating ward-based patients: Research protocol. Journal of Advanced Nursing, 66(4), 923-932.

McGaughey J, Blackwood B, O’Halloran \& Porter S. (2017). Early Warning Systems and rapid response to the deteriorating patient in hospital: a systematic realist review. (Submitted for publication to JAN along with this paper).

McNeill, G., \& Bryden, D. (2013). Do either early warning systems or emergency response teams improve hospital patient survival? A systematic review. Resuscitation, 84(12),1652-67.

MERIT study investigators. (2005). Introduction of the medical emergency team (MET) system: a cluster-randomised controlled trial. Lancet, 365,2091-2097.

Moon, A., Cosgrove, J.F., Lea, D., Fairs, A., \& Cressey, D.M. (2011). An eight year audit before and after the introduction of modified early warning score (MEWS) charts, of patients admitted to a tertiary referral intensive care unit after CPR. Resuscitation, 82, (2011) 150154. doi:10.1016/j.resuscitation.2010.09.480

National Health Service England. (2013). Everyone counts: Planning for Patients 2014/15 to 2018/19. London: NHS England.

National Institute for Health and Care Excellence. (2014). Safe staffing for nursing in adult inpatient wards in acute hospitals. Safe staffing guideline [SG 1]. ISBN: 978-1-4731-0646-8

National Quality Board. (2016). Supporting NHS providers to deliver the right staff, with the right skills, in the right place at the right time. Safe sustainable productive staffing. Retrieved

This article is protected by copyright. All rights reserved. 
from https://www.england.nhs.uk/wp-content/uploads/2013/04/nqb-guidance.pdf

Odell, M., Victor, C., \& Oliver, D. (2009). Nurses' role in detecting deterioration in ward patients: Systematic literature review. Journal of Advanced Nursing, 65(10),1992-2006.

Oglesby, K., Durham, L., Welch, J., \& Subbe, C.P. (2011). 'Score to door Time’, a benchmarking tool for rapid response systems: a pilot multi-centre service evaluation. Critical Care, 15, R180.

O’Leary, K.J., Ritter, C.D., Szekendi, M.K., Brinton, T.S., \& Williams, M.V. (2010). Teamwork on inpatient medical units: assessing attitudes and barriers. Quality \& Safety Health Care, 19,117-121.

Pattison, N., \& Eastham, E. (2011). Critical care outreach referrals: a mixed-method investigative study of outcomes and experiences. Nursing in Critical Care, 17(2), 71-82. doi: $10.1111 / \mathrm{j} .1478-5153.2011 .00464 . \mathrm{x}$

Pattison, N., O'Gara, G., \& Wigmore, T. (2015). Negotiating transitions: involvement of critical care outreach teams in end-of-life decision making. American Journal of Critical Care, 24 (3), 232-240. doi: http://dx.doi.org/10.4037/ajcc2015715

Pawson, R., \& Tilley, N. (1997). Realistic Evaluation. London: Sage.

Priestley, G., Watson, W., Rashidian, A., Mozley, C., Russell, D., Wilson, J., ....Pateraki J. (2004). Introducing Critical Care Outreach: a ward-randomised trial of phased introduction in a general hospital. Intensive Care Medicine, 30(7), 1398-1404.

NVivo qualitative data analysis Software. (2008). QSR International Pty Ltd. Version 8,QRS.

This article is protected by copyright. All rights reserved. 
Retrieved from www.qsrinternational.com/

Radeschia, G., Ursob, F., Campagnac, S., Berchiallac, P., Borgaa, S., Minaa, A., ...Sandroni C. (2015). Factors affecting attitudes and barriers to a medical emergency team among nurses and medical doctors: A multi-centre survey. Resuscitation, 88, 92-98.

http://dx.doi.org/10.1016/j.resuscitation.2014.12.027

Roberts, K.E, Bonafide, C.P., Paine, C.W, Paciotti, B., Tibbetts, K.M, Keren R., ....Holmes, J.H. (2014). Barriers to Calling for Urgent Assistance Despite a Comprehensive Pediatric Rapid Response System. American Journal of Critical Care, 23, 223-229.

Royal College of Physicians. (2012). National Early Warning Score (NEWS): Standardising the assessment of acute illness severity in the NHS. Report of a working party. London: Royal College of Physicians.

Sefton, G., McGratha, C., Tumea, L., Laneb, S., Lisboac, P.J.G., \& Carrol, E.D. (2015). What impact did a Paediatric Early Warning system have on emergency admissions to the paediatric intensive care unit? An observational cohort study. Intensive and Critical Care Nursing, 31, 91-99. http://dx.doi.org/10.1016/j.iccn.2014.01.001

Shearer, B., Marshall, S., Buist, M.D., Finnigan, M., Kitto, S, Hore, T., .... Ramsay W. (2012). What stops hospital clinical staff from following protocols? An analysis of the incidence and factors behind the failure of bedside clinical staff to activate the rapid response system in a multi-campus Australian metropolitan healthcare service. BMJ Quality \& Safety, $21,569-575$.

Smith, G.B., Osgood, V.M., \& Crane, S. (2002). ALERT $^{\mathrm{TM}}$ - a multiprofessional course in care of the acutely ill adult patient. Resuscitation, 52, 281-286.

This article is protected by copyright. All rights reserved. 
Smith, M.E.B., Chiovaro, J.C., O’Neil, M., Kansagara, D., Quiñones, A.R., Freeman, M., .....Slatore C.G. (2014). Early Warning System Scores for Clinical Deterioration in Hospitalized Patients: A Systematic Review. Annual of American Thoracic Society, 11 (9), 1454-1465. DOI: 10.1513/AnnalsATS.201403-102OC

Statistical Package for the Social Sciences (SPSS). (2008). Version 17. Chicago, Illinois, United States: SPSS Inc., Headquarters.

Stewart, D.W., Shamdasani, P.N., \& Rook, D.W. (2007). Focus group. Theory and Practice. Applied Social Research Methods Series ( $2^{\text {nd }}$ ed.). London: Sage.

Table 1: Participant sample and prior acute care training

\begin{tabular}{|c|c|c|c|c|c|c|c|c|c|c|c|c|c|}
\hline $\mathbb{S}_{\infty}$ & \multicolumn{13}{|c|}{ Policymaker Individual Interviews (n=14) } \\
\hline & \multirow{3}{*}{$\begin{array}{l}\text { Interviews } \\
\text { Individual }\end{array}$} & \multicolumn{6}{|c|}{ Case site 1} & \multicolumn{6}{|c|}{ Case site 2} \\
\hline & & \multirow[t]{2}{*}{ Sample } & \multicolumn{5}{|c|}{ Prior training } & \multirow[t]{2}{*}{ Sample } & \multicolumn{5}{|c|}{ Prior training } \\
\hline & & & $\begin{array}{l}\text { E } \\
W \\
S\end{array}$ & $\begin{array}{l}\mathrm{A} \\
\mathrm{L} \\
\mathrm{E} \\
\mathrm{R} \\
\mathrm{T}\end{array}$ & $\begin{array}{l}\text { I } \\
\text { L } \\
\text { S }\end{array}$ & $\begin{array}{l}\mathrm{O} \\
\mathrm{T} \\
\mathrm{H} \\
\mathrm{E} \\
\mathrm{R} \\
\end{array}$ & $\begin{array}{l}\mathrm{N} \\
\mathrm{V} \\
\mathrm{Q}\end{array}$ & & $\begin{array}{l}\text { E } \\
W \\
S\end{array}$ & $\begin{array}{l}\mathrm{A} \\
\mathrm{L} \\
\mathrm{E} \\
\mathrm{R} \\
\mathrm{T} \\
\end{array}$ & $\begin{array}{l}\text { I } \\
\text { L } \\
\text { S }\end{array}$ & $\begin{array}{l}\mathrm{O} \\
\mathrm{T} \\
\mathrm{H} \\
\mathrm{E} \\
\mathrm{R} \\
\end{array}$ & $\begin{array}{l}\mathrm{N} \\
\mathrm{V} \\
\mathrm{Q}\end{array}$ \\
\hline & $\begin{array}{l}\text { Medical \& Nursing Hospital } \\
\text { Managers, ALERT/EWS champions }\end{array}$ & 5 & 2 & 4 & 1 & 3 & & 5 & 1 & 2 & 2 & 2 & \\
\hline & Managers & 5 & 3 & 3 & 1 & 2 & & 5 & 5 & 5 & & 1 & \\
\hline & Junior doctors & 4 & & 4 & 4 & & & 5 & & 4 & 4 & 1 & \\
\hline \multirow{4}{*}{ 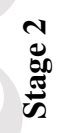 } & Focus groups & & & & & & & & & & & & \\
\hline & Nurses & 12 & 9 & 7 & & & & 11 & 5 & 6 & 1 & 1 & \\
\hline & Student nurses & 5 & & & & & & 2 & 2 & & & & \\
\hline & HCAs & 0 & & & & & & 4 & & & & & 3 \\
\hline
\end{tabular}

EWS, Early Warning System; ALERT, Acute Life-threatening Events: Recognition and Treatment; (A)ILS, Advanced / Intermediate Life Support course and or Instructor; Other, Specialist nurse training (ICU, Cardiology, Anaesthetics, Renal)or III Medical Patients Acute Care \& Treatment course (IMPACT); NVQ, National Vocational Training Level 2 or 3

This article is protected by copyright. All rights reserved. 
Table 2: RRS Theoretical Propositions

\begin{tabular}{|l|l|}
\hline RRS Component & Proposition \\
\hline Early Recognition & $\begin{array}{l}\text { Accurate, regular monitoring of vital signs on general hospital wards (Context) using } \\
\text { a standardised EWS tool alongside subjective assessment (Intervention) improves } \\
\text { recognition of patient deterioration (Outcome) by highlighting changes in } \\
\text { physiological parameters to nurses (Mechanism). }\end{array}$ \\
\hline Early Referral & $\begin{array}{l}\text { Predefined trigger thresholds with graded protocolised response strategies } \\
\text { (Intervention) empower nurses to refer patients (Mechanism) to an appropriate } \\
\text { member of staff (Context) who will attend within specified response times } \\
\text { (Outcome). }\end{array}$ \\
\hline Early Response & $\begin{array}{l}\text { Educational courses in caring for the acutely ill patient for all hospital staff at varying } \\
\text { levels of competence (Intervention) improves early intervention (Outcome) as an } \\
\text { appropriate member of staff with the required knowledge and skills (Mechanism) will } \\
\text { address deranged physiology according to the level of patient need at the beside } \\
\text { (Context). }\end{array}$ \\
\hline Improved outcome & $\begin{array}{l}\text { The use of a sensitive and specific EWS tool, with predefined triggers and graded } \\
\text { response algorithm (Intervention) improves early recognition, referral and response } \\
\text { to patient deterioration by staff (Mechanism) to reduce the incidence of cardiac } \\
\text { arrests, unplanned ICU admissions and unexpected deaths (Outcomes) in hospitalised } \\
\text { patients (Context). }\end{array}$ \\
\hline
\end{tabular}

Table 3: ALERT documentary analysis

\begin{tabular}{|l|l|l|}
\hline ALERT documentation & Case site 1 & Case site 2 \\
\hline Dates records reviewed & $28.7 .2003-29.5 .2008$ & $19.12 .2003-5.2008$ \\
\hline Total number trained & $775(15$ per course) & $599(20$ per course) \\
\hline Number of courses & 52 & 28 \\
\hline $\begin{array}{l}\text { Number of nurses trained } \\
\text { Others trained }\end{array}$ & $510(66 \%)$ & $384(64 \%)$ \\
& $244(31 \%)$ & $\begin{array}{l}124(21 \%) \\
\text { physio }(6.3), \text { ward sister }(4 \%), \\
\text { senior doctors }(2.4 \%)\end{array}$ \\
\hline Number of wards across hospital & CNP $(1 \%)$, lecturers $(0.3 \%)$, & 38 \\
\hline Wards x attendance at training & F2 doctors $(0.2 \%)$ & $\begin{array}{l}\text { Medical wards }(\mathrm{N}=30, \mathrm{~N}=25, \\
\mathrm{N}=24, \mathrm{n}=24), \text { Maternity } \\
(\mathrm{n}=26)\end{array}$ \\
\hline Courses block booked for doctors & A\&E $(\mathrm{n}=58), \mathrm{CCU}(\mathrm{n}=32)$, Cardiology $),$ ICU $(\mathrm{n}=23)$, Theatres $(\mathrm{n}=22)$ & 6 \\
\hline $\begin{array}{l}\text { Doctors participating in MDT } \\
\text { ALERT training }\end{array}$ & 26 out of 246 & 34 out of 140 \\
\hline
\end{tabular}

ALERT, Acute Life-threatening Events: Recognition and Treatment; CNP, Clinical Nurse Practitioner, A\&E, Accident and Emergency; MDT, Multidisciplinary team

This article is protected by copyright. All rights reserved. 
Table 4: Refined RRS CMOs

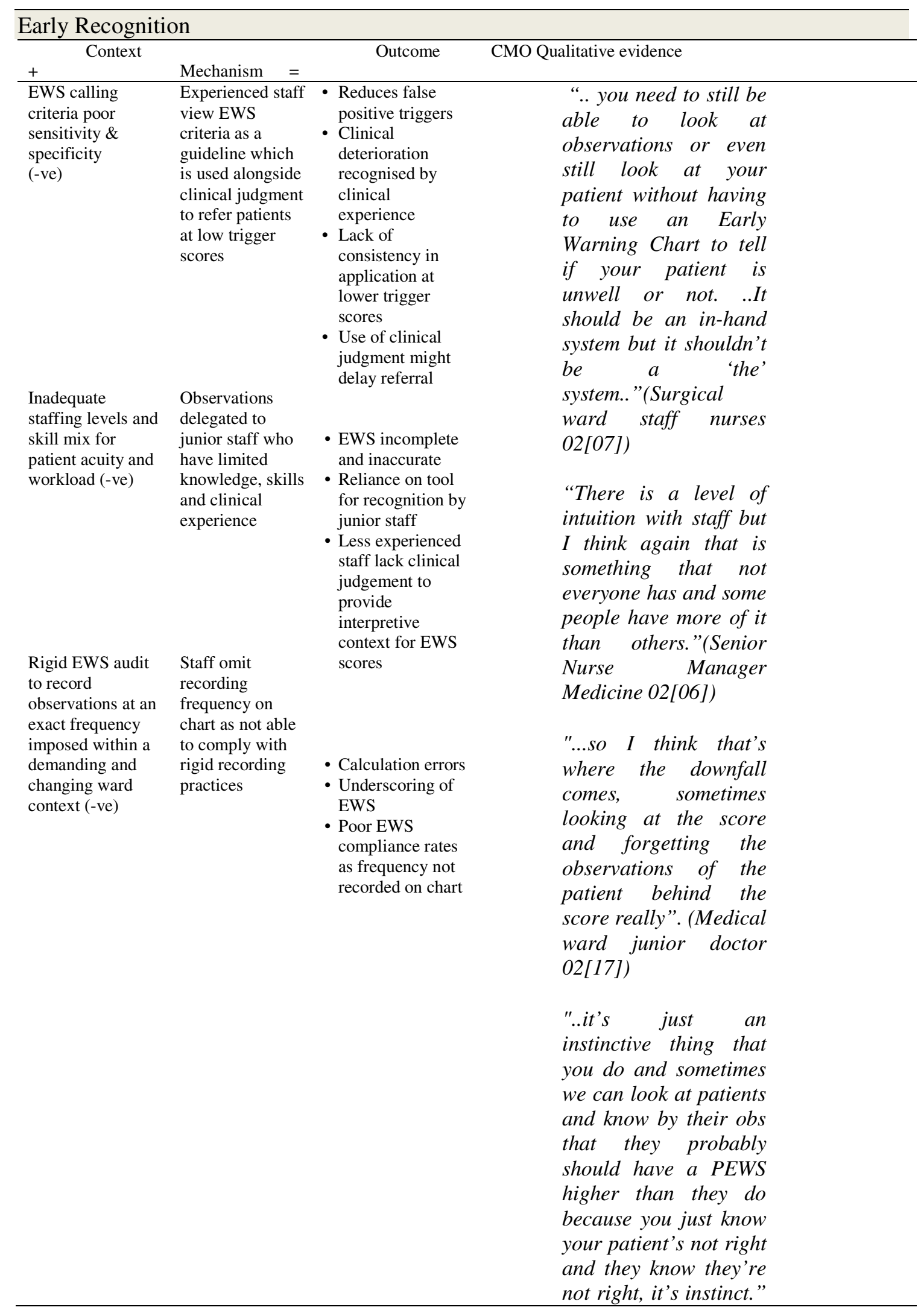

This article is protected by copyright. All rights reserved. 


\begin{tabular}{|c|c|c|c|}
\hline & & & $\begin{array}{l}\text { (Medical ward staff } \\
\text { nurses 01[09]) } \\
\text { "..what we found was, } \\
\text { repeatedly, that their } \\
\text { scores weren't being } \\
\text { done correctly, they } \\
\text { were missing some } \\
\text { parameters, the higher } \\
\text { the score the more } \\
\text { chance there was that } \\
\text { it wasn't added up } \\
\text { correctly and that was } \\
\text { a frequent finding that } \\
\text { whenever they had } \\
\text { totted them up they had } \\
\text { got the wrong number } \\
\text { and obviously that } \\
\text { could change the } \\
\text { response that was } \\
\text { required. .." (Senior } \\
\text { Nurse A 01[03]) }\end{array}$ \\
\hline \multicolumn{4}{|l|}{ Early referral } \\
\hline$+\quad$ Context & $\begin{array}{l}\text { Mechanism } \\
=\end{array}$ & Outcome & \\
\hline $\begin{array}{l}\text { Rigid } \\
\text { implementation of } \\
\text { protocol by nurses } \\
\text { to comply with } \\
\text { hospital policy (- } \\
\text { ve) }\end{array}$ & $\begin{array}{l}\text { Protocol } \\
\text { provides criteria } \\
\text { and empowers } \\
\text { experienced } \\
\text { nurses to refer } \\
\text { patients to senior } \\
\text { staff by } \\
\text { providing } \\
\text { objective data to } \\
\text { ground clinical } \\
\text { judgement. }\end{array}$ & $\begin{array}{l}\text { - Organisational } \\
\text { change shifted the } \\
\text { balance of power } \\
\text { /authority } \\
\text { regarding referral } \\
\text { timeframes } \\
\text { - Increased } \\
\text { confidence of } \\
\text { experienced nurses } \\
\text { to refer patients } \\
\text { without fear of } \\
\text { reprimand } \\
\text { - Inexperienced, } \\
\text { agency and HCA } \\
\text { staff fail } \\
\text { responsible for } \\
\text { delays in referral }\end{array}$ & $\begin{array}{l}\text { "It would probably be } \\
\text { your F1 because } \\
\text { they're ward based but } \\
\text { obviously you wouldn't } \\
\text { undermine them, you } \\
\text { would tell them but if } \\
\text { you felt that maybe they } \\
\text { weren't taking onboard } \\
\text { then you would just } \\
\text { bleep someone more } \\
\text { senior"(Surgical ward } \\
\text { sister O1 [19]) } \\
\text { "I think that the } \\
\text { structure of Mews or of } \\
\text { any type of early } \\
\text { warning system just } \\
\text { makes the decisions } \\
\text { easier for everybody } \\
\text { involved especially for } \\
\text { the people at the } \\
\text { bottom up, it gives } \\
\text { them the confidence to } \\
\text { say,... 'it's not me } \\
\text { making the decision to } \\
\text { call you, I have to call } \\
\text { you because the system } \\
\text { actually..., it gives you }\end{array}$ \\
\hline
\end{tabular}

This article is protected by copyright. All rights reserved. 


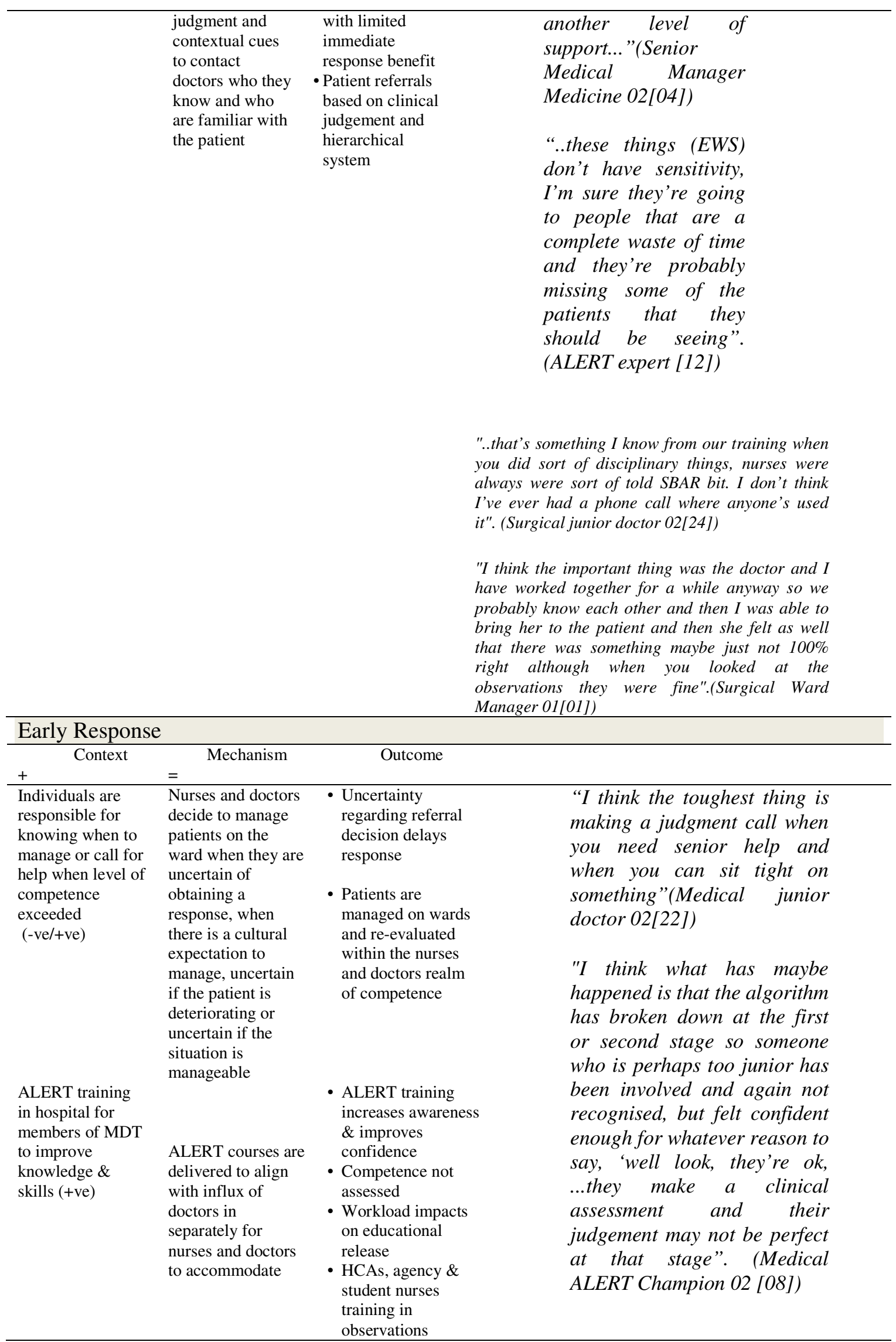

This article is protected by copyright. All rights reserved. 


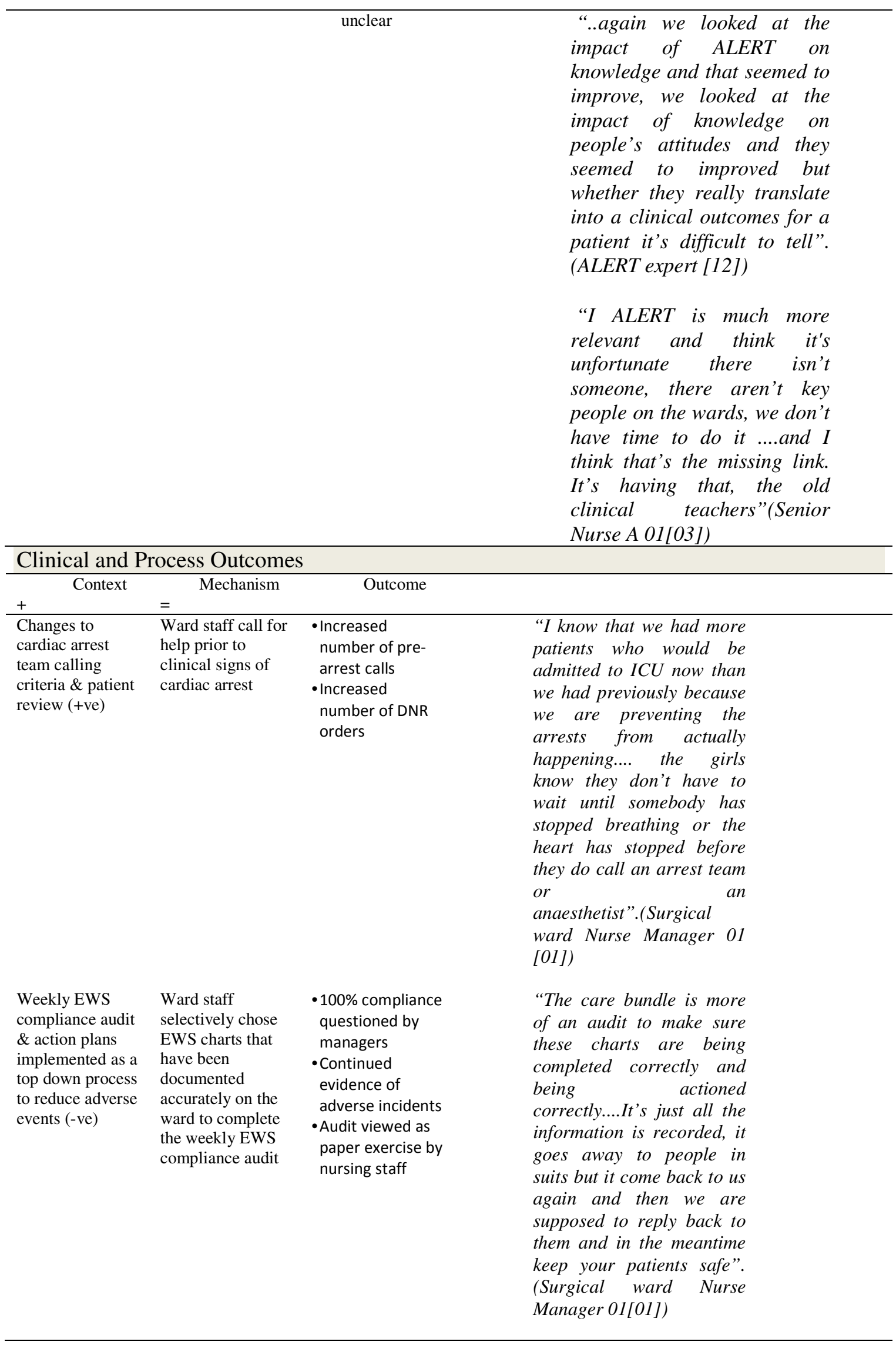

This article is protected by copyright. All rights reserved. 
Table 5: EWS compliance data across case sites

\begin{tabular}{|c|c|c|c|c|}
\hline EWS & Case site 1 & & Case site 2 & \\
\hline & Medical 01 & Surgical 01 & Medical 02 & Surgical 02 \\
\hline Data collection dates & May - Oct 10 & May-Oct 10 & May-Oct 10 & Sept- Oct10 \\
\hline Time span & 21 weeks & 21 weeks & 20 weeks & 8 weeks \\
\hline Initial compliance rate & $20 \%$ & $80 \%$ & $100 \%$ & $55 \%$ \\
\hline Range & $60-80 \%$ & $85-100 \% \%$ & $85-100 \%$ & $55-100 \%$ \\
\hline Noncompliant areas & $\begin{array}{l}\text { Frequency not } \\
\text { recorded; } \\
\text { Not recorded } \\
\text { to frequency; } \\
\text { no evidence of } \\
\text { action }\end{array}$ & $\begin{array}{l}\text { Frequency not } \\
\text { recorded }\end{array}$ & $\begin{array}{l}\text { Frequency not } \\
\text { recorded; vital } \\
\text { signs compliance; } \\
\text { not totalled }\end{array}$ & $\begin{array}{l}\text { Frequency not } \\
\text { recorded; not } \\
\text { recorded to } \\
\text { frequency; no } \\
\text { evidence of action; } \\
\text { not totalled }\end{array}$ \\
\hline Last compliance rate & $100 \%$ & $100 \%$ & $85 \%$ & $95 \%$ \\
\hline
\end{tabular}

Figure 1: Study Design

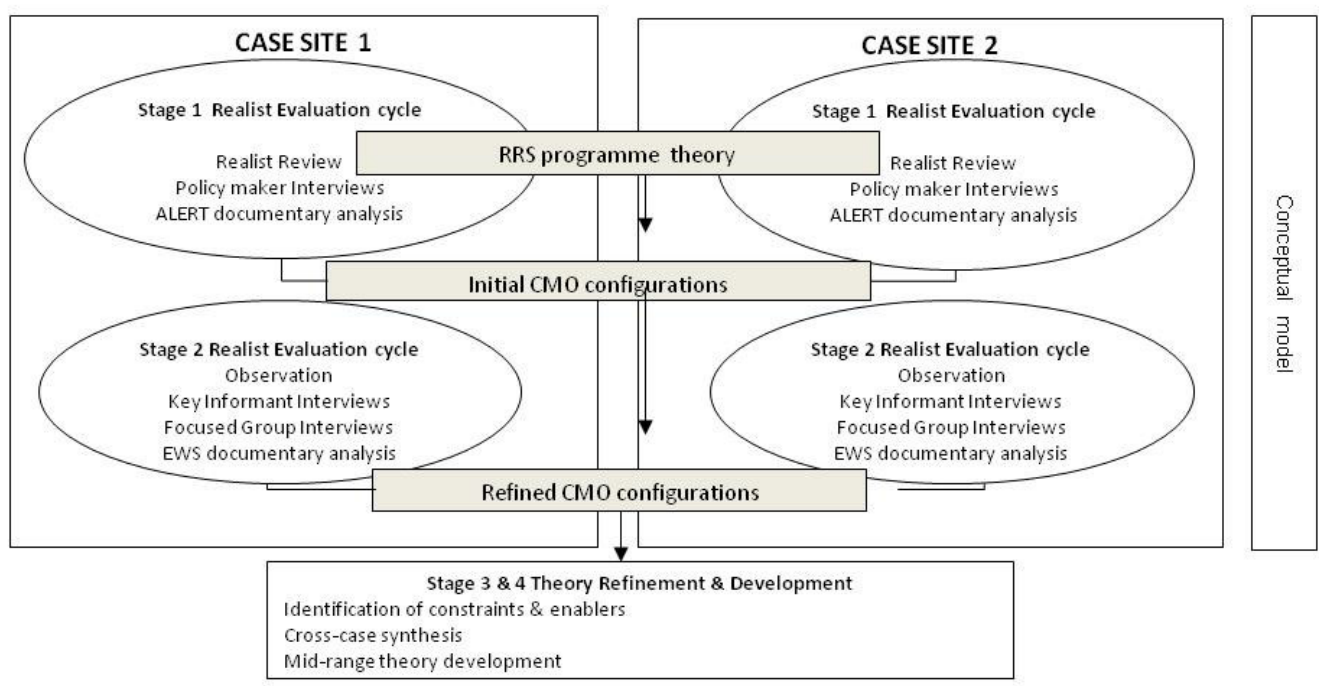

This article is protected by copyright. All rights reserved. 